\title{
Susceptibility and Vaccination Coverage of Vaccine Preventable Diseases among Health Care Workers in a Paediatric Tertiary Hospital, Egypt
}

\author{
Esraa Hemida, Mohamed Momen, Aisha Aboul Fotouh, Dina N. K. Boulos
}

Department of Community, Environmental and Occupational Medicine, Faculty of Medicine, Ain Shams University, Cairo, Egypt

Received: July, 2018 Accepted: September, 2018

\begin{abstract}
Background: Health-care workers (HCWs) represent a high risk group for acquiring vaccine-preventable diseases (VPDs). Objective: to determine susceptibility and vaccination coverage rates against VPDs among a group of health care workers in a tertiary care paediatric hospital, Egypt. Method: A cross sectional study was conducted at the Paediatric hospital of the Faculty of Medicine, Ain Shams University from July 2017 to November 2017. A Structured self-administered questionnaire including Sociodemographic characteristics, exposure to occupational VPDs infections and vaccination coverage was used. Results: Out of the $110 \mathrm{HCW}$ s enrolled, $50.0 \%$ were physicians, $34.5 \%$ were nurses and $15.5 \%$ were house keepers. The reported vaccination coverage rate was highest for Tuberculosis $(95.5 \%)$ followed by Hepatitis B $(86.4 \%)$ and lowest for chickenpox $(9.1 \%)$. HCWs reporting no history of disease or vaccination were considered as "potentially susceptible HCWs": $69.1 \%$ to rubella, $63.6 \%$ to mumps, $58.2 \%$ to measles, $54.5 \%$ to chickenpox, $13.5 \%$ to hepatitis B and $1.8 \%$ to tuberculosis. The main reasons for non-immunization were lack of vaccine provision by the hospital (from $63.6 \%$ for influenza to $53.5 \%$ for hepatitis B), lack of knowledge of vaccine recommendation (from $89.5 \%$ MMR to $43.2 \% \%$ for influenza), fear of vaccine side effects (from $33.3 \%$ for hepatitis B to $4.5 \%$ for influenza) and $10.2 \%$ reported that they don't get influenza vaccine because they think that it is not a serious disease. Compared with nurses and housekeepers, physicians were more likely to have been vaccinated for hepatitis $\mathrm{B}, \mathrm{MMR}$ and chickenpox $(\mathrm{P}<0.01)$. Conclusion: The current study revealed that the vaccination coverage for most of the VPDs is generally below expectations. Raising awareness of the recommended vaccines in addition to providing them free of charge or at a reduced price by the hospital administration can improve the vaccination coverage among HCWs.
\end{abstract}

Keywords: Health Care Workers; Vaccination coverage; Vaccine Preventable Diseases; Vaccine Preventable Diseases susceptibility

Corresponding Author: Dina N. K. Boulos, E-mail: dnkamel@med.asu.edu.eg

\section{Introduction}

Health-care workers (HCWs) represent a high risk group for acquiring vaccinepreventable diseases (VPDs). ${ }^{1}$ Healthcare workers comprise all personnel who have contact with patients including a variety of professionals with different levels of exposure and patient contact, such as doctors, nurses, physiotherapists, laboratory technicians, dietitians, cleaning and catering. ${ }^{2,3}$ The World Health Organization (WHO) estimates that globally around 59 million HCWs are daily exposed to a multitude of occupational hazards. The most prevalent hazard is the risk of exposure to occupational infections as a result of exposure to infected patients and/or infectious materials. ${ }^{4,5}$ 
The logic for immunization of HCWs relies on two basic pillars: The first one is the fact that HCWs are at increased risk for acquiring occupational VPDs. Previous studies reveal higher risk for acquisition of measles and influenza compared to adults working in nonhealthcare settings. ${ }^{6,7}$ In the current vaccine era, the national expanded program of immunization resulted in decrease of VPDs. As a result average patient age has increased in many developed countries, shifting from the first to the third decade of life; thus, it is expected that the severity of several formerly childhood VPDs will increase. ${ }^{8}$ Health Care Workers (HCWs) provide health care to many patients with multiple vulnerabilities for a serious disease course, complications, or even death because of their age (e.g., neonates, young infants, elderly) and/or underlying conditions (e.g., pregnancy, immunecompromised status, chronic diseases). ${ }^{9}$ In addition, HCWs have been traced as the primary source of infection in many outbreaks of VPDs, including influenza, pertussis, measles, rubella, varicella, hepatitis A, and hepatitis $\mathrm{B} .^{9,10-13}$ Outbreaks of VPDs in healthcare facilities are also associated with absenteeism among HCWs, interruption of health services, costs of testing, prophylaxis, treatment, infection-control measures, and contact tracing. ${ }^{10-12,14}$ Thus immunization of HCWs is justified as a primary prevention measure to prevent the transmission of VPDs to susceptible patients, their colleagues, and families. ${ }^{15-}$ 17

Several researches from different countries reveal significant immunity gaps against most of the VPDs. Susceptibility to infection rates of HCWs varied for different VPDs and among different studies ranging from $4.6 \%$ to $17 \%$ for measles, $15.7 \%$ to $25 \%$ for mumps, $4.5 \%$ to $18.6 \%$ for rubella, $4.1 \%$ to $16.7 \%$ for chicken pox, $48.3 \%$ to $68.8 \%$ for pertussis, $22.6 \%$ to $35 \%$ for hepatitis $\mathrm{B}$, and $21.2 \%$ to $64.3 \%$ for tetanus and diphtheria. ${ }^{18-20}$ Globally, reported vaccination rates are below targets ranging from $18.8 \%$ to $70.5 \%$ against measles and mumps, $22.2 \%$ to $70.5 \%$ against rubella, $1.9 \%$ to $3 \%$ against varicella, $40 \%$ to $95 \%$ against hepatitis B. ${ }^{19-23}$ Similarly reported influenza vaccination uptake by $\mathrm{HCW}$ s remains low over the last few years, ranging from 5\% to $42 \%$ in many countries. ${ }^{19,23}$

Health care workers working in paediatric departments get more in contact with many VPDs during their daily patients' contacts. Ensuring that HCWs are immune to VPDs is an essential part of employee health programs. Prevention of illness through comprehensive HCWs immunization programs is by far more cost effective than case management and outbreak control. ${ }^{24,25}$

Nationally and regionally available researches on the susceptibility and the vaccination coverage rates among healthcare workers are scarce.

The current study aims to determine HCWs susceptibility and vaccination coverage rates against vaccine preventable diseases among a group of health care workers in a tertiary care paediatric hospital, Egypt.

\section{Method}

A cross sectional study was conducted at the Paediatric hospital of the Faculty of Medicine, Ain Shams University, Egypt. It is a tertiary care hospital having nine units with a total capacity of 200 beds (inpatients, incubators and intensive care unit). The outpatient clinic flow is around 77.000 patients per year. The Emergency department receives around 35.000 patients per year and the average number of admissions per year is 8000 patients.

Study population, Sample size and tool: From July 2017 to November 2017 all Healthcare workers (Physicians, nurses and housekeepers) who are in contact with 
patients and working for at least 6 months were recruited through visits on 3 days each week to obtain the required information.

A sample of 108 (approximated to 110) HCWs produces a two sided $95 \%$ confidence interval with a width equal to 0.2 when the sample proportion is $0.5 \%$ (95\% CI 0.4-0.6).

A Structured self-administered anonymous questionnaire was used to collect data from participating healthcare workers (self-administered aided questionnaire for housekeepers only) including Socio-demographic characteristics, occupational vaccine preventable diseases infections exposure and vaccination coverage.

For the calculation of the reported vaccination coverage, the numerator was based on the number of HCWs who reported being vaccinated and the denominator resulted from the number of HCWs who reported no history of disease. Only HCWs reporting no history of disease or vaccination were considered potentially susceptible.

\section{Ethical considerations:}

The protocol of the study was submitted to the Ethical Review Committee at the Faculty of Medicine, Ain Sham University prior to the study. It was an exempted research as an anonymous questionnaire was used. A verbal informed consent was obtained from each participant after the explanation of the nature of the study and assuring that participation is voluntary. The confidentiality of data was also assured. An administrative approval from the Paediatric hospital manager was obtained as well.

Data Management:
The collected data was revised, coded, tabulated and introduced to personal computer then analysed using SPSS program (Statistical Package for Social Sciences) for windows Version 20. Qualitative data were presented as frequencies and percentages. Chi square test and fisher exact test were used as tests of significance and $\mathrm{p}<0.05$ was considered significant.

\section{Results:}

Table 1: Socio- Demographic and occupation Characteristics of studied HCWs at Pediatric tertiary care hospital, $\operatorname{Egypt}(\mathbf{N}=110)$

\begin{tabular}{lrc}
\hline \multicolumn{1}{c}{ Characteristics } & N & \% \\
\hline Gender & & \\
\hline Male & 24 & 21.8 \\
Female & 86 & 78.2 \\
\hline Age group (Years) & & \\
\hline $20-29$ & 71 & 64.5 \\
$30-39$ & 18 & 16.4 \\
$40-49$ & 19 & 17.3 \\
$50+$ & 2 & 1.8 \\
\hline Profession & & \\
\hline Nurse & 38 & 34.5 \\
Physician & 55 & 50.0 \\
Housekeeper & 17 & 15.5 \\
\hline Duration of & professional & career \\
(years) & & \\
\hline Mean+ SD & $2.9 \pm 1.4$ \\
\hline
\end{tabular}

Out of the $110 \mathrm{HCW}$ s enrolled, $78.2 \%$ ( $\mathrm{n}=$ 86 ) were females and $64.5 \%$ of the study participants were aged from 20 to 29 years $(n=71)$. Of the studied HCWs $50.0 \%$ were physicians, $34.5 \%$ were nurses and $15.5 \%$ were house keepers. The mean $( \pm \mathrm{SD})$ duration of professional career was $2.9 \pm 1.4$ years (Table 1$)$.

The reported vaccination coverage rate was highest for Tuberculosis $(95.5 \%)$ followed by Hepatitis B (86.4\%) and lowest for chicken pox (9.1\%). Potentially susceptible HCWs rate was

Table 2. Reported history of infection, reported vaccination, and HCWs potentially susceptible of studied HCWs at Pediatric tertiary care hospital, Egypt ( $N=110)$

\begin{tabular}{cccc} 
Disease & $\begin{array}{c}\text { Reported history of } \\
\text { infection }\end{array}$ & $\begin{array}{c}\text { Reported } \\
\text { vaccination }\end{array}$ & $\begin{array}{c}\text { HCWs potentially } \\
\text { susceptible }\end{array}$ \\
\hline \hline
\end{tabular}




\begin{tabular}{lccc}
\hline & $\mathbf{N}(\boldsymbol{\%})$ & $\mathbf{N}(\boldsymbol{\%})$ & $\mathbf{N}(\boldsymbol{\%})$ \\
\hline Hepatitis B & & $95(86.4)$ & $15(13.5)$ \\
Measles & $0(0)$ & $14(12.7)$ & $64(58.2)$ \\
Mumps & $12(10.9)$ & $14(12.7)$ & $70(63.6)$ \\
Rubella & $12(10.9)$ & $12(10.9)$ & $76(69.1)$ \\
Chicken Pox & $4(3.6)$ & $10(9.1)$ & $60(54.5)$ \\
Tuberculosis & $35(31.8)$ & $105(95.5)$ & $2(1.8)$ \\
\hline
\end{tabular}

higher in the case of Rubella $(69.1 \%)$ followed by Mumps (63.6\%). As regards, history of natural infection, a history of measles, mumps, rubella, varicella, hepatitis B or Tuberculosis was reported by $10.9 \%, 10.9 \%, 3.6 \%, 31.8 \%, 0 \%$ and $2.7 \%$ of $\mathrm{HCWs}$, respectively reported history of infection. On the other hand, HCWs reporting no history of disease or vaccination were considered as "potentially susceptible HCWs": 69.1\% to rubella, 63.6 . \% to mumps, $58.2 \%$ to measles, $54.5 \%$ to chicken pox, $13.5 \%$ to hepatitis $\mathrm{B}$ and $1.8 \%$ to tuberculosis (Table 2).

As for the potentially susceptible HCWs (neither history of disease nor reported vaccination) A statistically significant higher percentage of HCWs potentially susceptible to hepatitis B, measles, mumps, rubella and chicken pox was observed in nurses accounting for $60 \%$ , $53.1 \%$. 55.7\%, 52.6\% and 53.3\%, respectively $(\mathrm{p}<0.05)$. A statistically significant higher percentage $(55 \%)$ of HCWs potentially susceptible to chicken pox was observed in those having a profession duration of $1-5$ years $(\mathrm{p}<$ 0.05). (Table 3).

The main reasons for no immunization as mentioned by study participants as lack of vaccine provision by the hospital (from $63.6 \%$ for influenza to $53.5 \%$ for hepatitis B), lack of knowledge of vaccine recommendation (from $89.5 \% \mathrm{MMR}$ to $43.2 \% \%$ for influenza), fear of vaccine side effects (from $33.3 \%$ for hepatitis B to $4.5 \%$ for influenza) and $30.7 \%$ reported that they don't get influenza vaccine because they think that it is not a serious disease (Figure 1).
Compared with nurses and housekeepers, physicians were more likely to have been vaccinated for hepatitis $B, M M R$ and chicken Pox $(\mathrm{P}<0.01)$ (Table 4).

\section{Discussion:}

Recently safety in health care facilities has gained great attention and has been a basic component of clinical practice. Vaccination of HCWs is considered for self-protection, as well as for protection of susceptible patients, in addition to providing indirect protection of general population through herd immunity. ${ }^{27-28}$ The findings of the current study show an overall, significant levels of susceptibility and insufficient rates of vaccination for VPDs among a group of HCWs in a tertiary care paediatric hospital. The reported vaccination coverage rate for Hepatitis B was $86.4 \%$. This is much higher than Talaat et al. (2003) study carried out on a sample of HCWs from different types of health care facilities in 2 governorates (one from Nile Delta and the second one from Upper Egypt). In this study hepatitis B vaccination was reported by only $15.8 \%$ of study participants. ${ }^{29}$ Another study carried among HCWs in general surgery department at Assuit University by Zayet et al. (2015) revealed that $61.4 \%$ of HCWs reported hepatitis B vaccination. ${ }^{30}$

Similarly, the current study finding is higher than what has been shown in studies that enrolled HCWs in Italy and HCWs in a paediatric departments in 
Table 3. Potentially susceptible HCWs (neither history of disease nor reported vaccination) of studied HCWs at Pediatric tertiary care hospital, Egypt (N=110)

\begin{tabular}{|c|c|c|c|c|c|c|c|c|c|c|c|c|c|c|c|c|c|c|c|}
\hline & & \multicolumn{3}{|c|}{ Hepatitis B } & \multicolumn{3}{|c|}{ Measles } & \multicolumn{3}{|c|}{ Mumps } & \multicolumn{3}{|c|}{ Rubella } & \multicolumn{3}{|c|}{ Chicken Pox } & \multicolumn{3}{|c|}{ Tuberculosis } \\
\hline & & $\%$ & $\mathbf{X}^{2}$ & $p$ value & $\%$ & $\mathbf{X}^{2}$ & $p$ value & $\%$ & $\mathbf{X}^{2}$ & $p$ value & $\%$ & $\mathbf{X}^{2}$ & $p$ value & $\%$ & $\mathbf{X}^{2}$ & $p$ value & $\%$ & $\mathrm{X}^{2}$ & $p$ value \\
\hline Total & & \multicolumn{2}{|c|}{$13.6(n=15)$} & \multicolumn{3}{|c|}{$58.2(\mathrm{n}=64)$} & \multicolumn{3}{|c|}{$63.6(n=70)$} & \multicolumn{3}{|c|}{$69.1(\mathrm{n}=76)$} & \multicolumn{3}{|c|}{$54.5(\mathrm{n}=60)$} & \multicolumn{3}{|c|}{$1.8(\mathrm{n}=2)$} & \\
\hline \multirow[b]{2}{*}{ Sex } & Male & 20 & \multirow[b]{2}{*}{0.034} & \multirow[b]{2}{*}{0.579} & 21.8 & \multirow[b]{2}{*}{0} & \multirow[b]{2}{*}{0.986} & 21.4 & \multirow[b]{2}{*}{0.017} & \multirow[b]{2}{*}{0.896} & 21.1 & \multirow[b]{2}{*}{0.084} & \multirow[b]{2}{*}{0.771} & 31.7 & \multirow[b]{2}{*}{7.506} & \multirow[b]{2}{*}{0.01} & 0 & \multirow[b]{2}{*}{0.568} & \multirow[b]{2}{*}{0.451} \\
\hline & Female & 80 & & & 78.2 & & & 78.6 & & & 78.9 & & & 68.3 & & & 100 & & \\
\hline \multirow{3}{*}{ Age (years) } & $21-30$ & 73.3 & \multirow{3}{*}{3.347} & \multirow{3}{*}{0.335} & 60.9 & \multirow{3}{*}{3.038} & \multirow{3}{*}{0.388} & 60 & & & 61.8 & & & 58.3 & & & 50 & & \\
\hline & $31-40$ & 6.7 & & & 20.3 & & & 17.1 & & & 14.5 & & & 18.3 & & & 50 & & \\
\hline & $50+$ & 6.7 & & & 3.1 & & & 2.9 & & & 2.6 & & & 1.7 & & & 0 & & \\
\hline & Physician & 6.7 & & & 23.4 & & & 22.9 & & & 27.6 & & & 25 & & & 50 & & \\
\hline Profession & Nurse & 60 & 8.16 & 0.01 & 53.1 & 12.076 & 0.002 & 55.7 & 13.315 & 0.001 & 52.6 & 6.661 & 0.035 & 53.3 & 7.071 & 0.032 & 50 & 0.705 & 0.796 \\
\hline & Housekeeper & 33.3 & & & 23.4 & & & 21.4 & & & 19.7 & & & 21.7 & & & 0 & & \\
\hline & $<1$ & 0 & & & 6.3 & & & 5.7 & & & 5.3 & & & 3.3 & & & 0 & & \\
\hline & $1-5$ & 80 & & & 54.7 & & & 52.9 & & & 55.3 & & & 55 & & & 50 & & \\
\hline Seniority (years) & $11-15$ & 13.3 & 2.312 & 0.789 & 15.6 & 4.055 & 0.555 & 14.3 & 6.698 & 0.223 & 13.2 & 0.573 & 0.507 & 8.3 & 13.292 & 0.014 & 50 & 4.451 & 0.653 \\
\hline & $16-20$ & 0 & & & 7.8 & & & 5.7 & & & 6.6 & & & 8.3 & & & 0 & & \\
\hline & $20+$ & 6.7 & & & 7.8 & & & 12.9 & & & 11.8 & & & 15 & & & 0 & & \\
\hline
\end{tabular}


Table 4. Vaccination coverage rate by professional career of studied HCWs at Paediatric tertiary care hospital, Egypt $(\mathrm{N}=110)$

\begin{tabular}{lrrccl}
\hline & $\begin{array}{c}\text { Physicians } \\
\mathbf{N}(\%)\end{array}$ & $\begin{array}{c}\text { Nurses } \\
\mathbf{N}(\%)\end{array}$ & $\begin{array}{c}\text { Housekeepers } \\
\mathbf{N}(\%)\end{array}$ & $\begin{array}{c}\text { Fisher's } \\
\text { Exact }\end{array}$ & P value \\
\hline HB vaccine & $37(97.3)$ & $46(83.6)$ & $12(70.6)$ & 8.160 & $<0.01$ \\
MMR vaccine & $12(31.5)$ & $2(3.6)$ & 0 & 21.750 & $<0.01$ \\
Rubella vaccine & $8(21.1)$ & $4(7.3)$ & 0 & 6.499 & 0.140 \\
Chicken pox vaccine & $8(21.1)$ & $2(3.6)$ & 0 & 8.474 & $<0.01$ \\
TB vaccine & $34(89.5)$ & $54(98.2)$ & $17(100)$ & 3.634 & 0.140 \\
Seasonal Flu vaccine & $5(13.2)$ & $12(21.8)$ & $5(29.4)$ & 2.259 & 0.377 \\
\hline
\end{tabular}

Greece revealing a vaccination coverage rate for hepatitis $\mathrm{B}$ of $70.1 \%$ and $69.2 \%$ respectively. ${ }^{21,26}$

On the other hand the current study finding for hepatitis $\mathrm{B}$ vaccination coverage rate is slightly lower than the rate revealed by a study conducted in a tertiary care hospital in Riyadh, Saudi Arabia reporting that hepatitis B vaccination coverage was $95 \%$ among HCWs. ${ }^{24}$

The high coverage rate of Hepatitis $B$ vaccine reported in the current study in addition to the increasing trend from previous studies was due to strict regulations and recommendations of HCWs vaccinations by Ministry of Health and population (MOHP) in addition to many hepatitis $b$ vaccination campaigns targeting HCWs especially at university hospitals as well as targeting students of faculty of Medicine and nursing schools. These activities as well as the inclusion of hepatitis $B$ vaccine through the compulsory national expanded program of immunization in 1991 made this increasing trend. ${ }^{31}$

Influenza vaccine has seasonal protection validity. Each year HCWs are required to receive the new vaccine as this is the only vaccine that needs yearly administration. As a result, receiving the influenza vaccine can be a surrogate measure for the "active protection behaviour" among HCWs. ${ }^{1}$
In the present study, vaccination coverage for influenza for the preceding year was $20 \%$ (data not shown). This finding is much lower than the influenza immunization rate reported from many studies ranging from as low as $24.8 \%$ in an Italian study to $50.8 \%$ and $80 \%$ in a Saudi and Australian studies respectively. ${ }^{24,26,32}$

The results of the current study show that potentially susceptible HCWs (without history of disease or vaccination) constitute significant proportion of the hospital HCWs at the Paediatric university hospital ranging from lowest as $1.8 \%$ and $13.5 \%$ for tuberculosis and hepatitis $\mathrm{B}$ respectively to highest as $69.1 \%$ and $63.6 \%$ for rubella and mumps respectively. These findings are higher than the results of Taddei et al. (2014) revealing that susceptible HCWs were $19.7 \%$ and $25.1 \%$ for rubella and mumps, respectively. ${ }^{34}$

The current study finding is similar to an Italian study ${ }^{1}$ revealing that $16.8 \%$ of HCWs are susceptible to hepatitis B. Although one of the current study participants reported previous history of hepatitis B infection, lower susceptibility to it may be due to high vaccination coverage rate for hepatitis $\mathrm{B}$ that may be explained by the aforementioned reasons. Compared with nurses and housekeepers, physicians were more likely to have been vaccinated for hepatitis $B$, MMR and 
chicken Pox $(\mathrm{P}<0.01)$. This finding

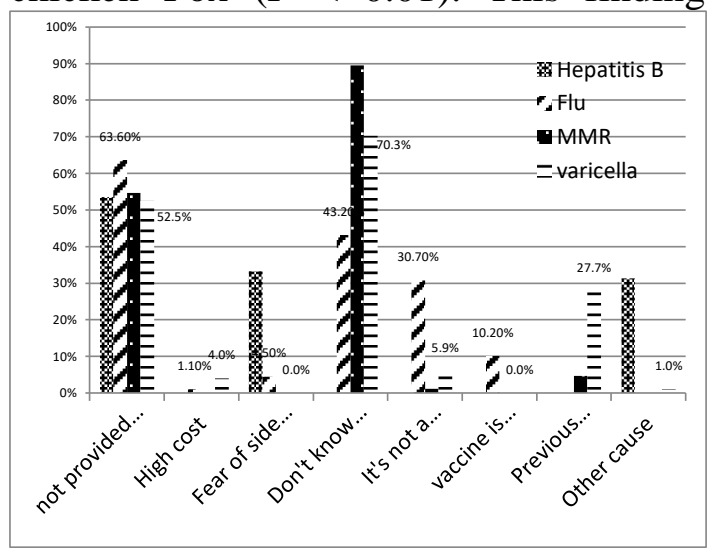

Figure 1. Reported reasons for no vaccination in each disease by studied HCWs at Paediatric tertiary care hospital, Egypt (N=110)

disagrees with Fortunato et al. (2015) revealing that nurses were significantly more likely to have been vaccinated against these three VPDs. ${ }^{26}$

In the present study the only statistically significant higher percentage of HCWs potentially susceptible to studied VPDs (except for Tuberculosis) was observed among nurses. This agrees with Taddei et al. (2014) study reporting that as regards profession, the percentage of potentially susceptible physicians was lower for only chicken pox $(\mathrm{P}<0.05)$ in addition to revealing that males were significantly more susceptible to rubella. ${ }^{33}$

The main reported reasons for not receiving the vaccine for each VPDs varied from lack of provision of immunization (ranging from $52.5 \%$ for varicella to $63.6 \%$ for influenza), Lack of knowledge that the vaccine is recommended (from $0 \%$ for hepatitis b to $43.2 \%$ for influenza and $89.5 \%$ for MMR). In addition, $10.2 \%$ of studied HCWs reported that they don't get influenza vaccine because they think that it is not a serious disease The current study findings suggest that a knowledge gap exist regarding awareness of vaccination recommendations for $\mathrm{HCWs}$ except for hepatitis B. Health Care Workers perception of the seriousness of
VPDs can be an important factor in determining uptake of $\mathrm{HCW}$ s vaccination and should be considered in awareness programs.

\section{Limitations of the study:}

The study results are limited by depending on self-reported vaccination history and previous history of infection in addition, the study population is limited to the HCWs in a tertiary paediatric hospital.

\section{Conclusion}

The current study revealed that even though vaccines are available for many infectious diseases, the reported vaccination coverage for most of the VPDs is generally below expectations. Although certain vaccines like hepatitis B had a high coverage other vaccines like measles or influenza showed much lower vaccination rates.

Raising awareness of the recommended vaccines in addition to providing them free of charge or at a reduced price by the hospital administration can improve the vaccination coverage among HCWs. Vaccination rates among $\mathrm{HCWs}$ should be regularly measured and reported, this information might be useful to promote compliance with vaccination policies and plan future awareness campaigns. Medical students must be considered a priority group for campaigns promoting vaccination.

\section{References:}

1. Scatigna M, Fabiani L, Micolucci G, Santilli F, Mormile P \& Giuliani AR. Attitudinal variables and a possible mediating mechanism for vaccination practice in health care workers of a local hospital in L'Aquila (Italy). Hum Vaccines Immunother [Internet]. 2017;13(1):198-205. Available from: http://dx.doi.org/10.1080/21645515.2016.12 25638

2. Dash GP, Fauerbach L, Pfeiffer J, Soule B, Bartley J, Barnard BM, Lundstrom T \&Andrus M; Association for Professionals in Infection Control and Epidemiology. APIC position paper: Improving health care worker 
influenza immunization rates. Am J Infect Control. 2004 May;32(3):123-5. PubMed PMID: 15153921.

3. Centers for Diease Control and Prevention. Immunization of Health-Care Personnel Recommendations of the Advisory Committee on. US Dep Heal Hum Serv [Internet]. 2011;60(7):1-45. Available from: http://www.ncbi.nlm.nih.gov/pubmed/22108 587

4. World Health Organization (WHO). Occupational health. Health workers. Health worker occupational heath.

5. Galanakis E, Jansen A, Lopalco PL \& Giesecke J. Ethics of mandatory vaccination for health care workers. Eurosurveillance. 2013;18(45): 1-8.

6. Steingart KR, Thomas AR, Dykewicz CA $\&$ Redd SC. Transmission of measles virus in healthcare settings during a communitywide outbreak. Infect Control Hos Epidemiol. 1999 Feb;20(2):115-9. PubMed PMID: 10064215. 7. Kuster SP, Shah PS, Coleman BL, Lam PP, Tong A, Wormsbecker A \& McGeer A. Incidence of influenza in healthy adults and healthcare workers: a systematic review and meta-analysis. PLoS One. 2011;6(10):e26239. doi: 10.1371/journal.pone.0026239. Epub 2011 Oct 18. Review. PubMed PMID: 22028840; PubMed Central PMCID: PMC3196543.

8. Fefferman NH \& Naumova EN. Dangers of vaccine refusal near the herd immunity threshold: a modelling study. Lancet Infect Dis. 2015 Aug;15(8):922-6. doi: 10.1016/S1473-3099(15)00053-5. Epub 2015 May 14. PubMed PMID: 25981883.

9. Carlson,A.L. \& Perl,T.M. Health- care workers as source of hepatitis Band $\mathrm{C}$ virus transmission. Clin. Liv. Dis. 2010, 14, 153168.

10. Maltezou, H.C.; Ftika, L. \& Theodoridou, M. Nosocomial pertussis in neonatal units. J.Hosp. Infect. 2013, 85, 243-248.

11. Maltezou, H.C \& Wicker, S. Measles in health care settings. Am. J.Infect. Control 2013, 41, 661-663.

12. Maltezou, H.C. \& Drancourt, M. Nosocomial influenza in children. J. Hosp. Infect. 2003, 55, 83-91. [CrossRef]

13. Ridgway, J.P.; Bartlett, A.H.; GarciaHouchins, S.; Carino, S.; Enriquez, A.; Marrs, R.; Perez, C.; Shah, M.; Guenette, C. \& Mosakowski, S. Influenza among afebrile and vaccinated healthcare workers. Clin. Infect. Dis. 2015, 60, 1591-1595.

14. Wendorf, K.A.; Kay, M.; OrtegaSanchez, I.R.; Munn, M. \& Duchin, J. Cost of measles containment in an ambulatory pediatric clinic. Pediatr. Infect. Dis. J. 2015, 36, 589-593.

15. Saxen, H. \& Virtanen, M. Randomized, placebo-controlled double blind study on the efficacy of influenza immunization on absenteeism of health care workers. Pediatr. Infect. Dis. J. 1999, 18, 779-783.

16. Wilde, J.A.; McMillan, J.A.; Serwint, J.; Butta, J.; O'Riordan, M.A \& Steinhoff, M.C. Effectiveness of influenza vaccine in health care professionals: a randomized trial. JAMA 1999, 281, 908-913.

17. Van Buynder, P.G.; Konrad, S.; Kersteins, F.; Preston, E.; Brown, P.D.; Keen, D. \& Murray, N.J. Healthcare worker influenza immunization vaccinate or mask policy: Strategies for cost effective implementation and subsequent reduction in staff absenteeism due to illness. Vaccine 2015, 33, 1625-1628.

18. Botelho-Nevers, E.; Cassir, N.; Minodier, P.; Laporte, R.; Gautret, P.; Badiaga, S.; Thiberville, D.J.; Ninove, L.; Charrel, R \& Brouqui, P. Measles among healthcare workers: A potential for nosocomial outbreaks. Euro Surveill. 2011.

19. Little, K.E.; Goodridge, S.; Lewis, H.; Lingard, S.W.; Din, S.; Tidley, M.; Roberts, R.J.; Williams, N.S. \& Hayes, S. Occupational vaccination of health care workers: Uptake, attitudes and potential solutions. Public Health 2015, 29, 755-762.

20. Maltezou, H.C.; Gargalianos, P.; Nikolaidis, P.; Katerelos, P.; Tedoma, N.; Maltezos, E. \& Lazanas, M. Attitudes towards mandatory vaccination and vaccination coverage against vaccine-preventable diseases among health-care workers in tertiary-care hospitals. J. Infect. 2012, 64, 319-324.

21. Maltezou, H.C.; Lourida, A.; Katragkou, A.; Grivea, I.N.; Katerelos, P.; Wicker, S.; Syrogiannopoulos, G.A.; Roilides, E. \& Theodoridou, M. Attitudes regarding occupational vaccines and vaccination coverage against vaccine-preventable diseases among healthcare workers working in pediatric departments in Greece. Pediatr. Infect. Dis. J. 2012, 31, 623-625.

Vol. 38 No. 1 January

2020 
22. Freund, R.; Krivine, A.; Prévost, V.; Cantin, D.; Aslangul, E.; Avril, M.F.; Claessens, Y.E.; Rozenberg, F.; Casetta, A \& Baixench, M.T. Measles immunity and measles vaccine acceptance among healthcare workers in Paris, France. J. Hosp. Infect. 2013, 84, 38-43.

23. Ryser, A.J \& Heininger, U. Comparative acceptance of pertussis and influenza immunization among health-care personnel. Vaccine 2015, 33, 5350-5356.

24. Anwar M; Hathout H M; El-Dalatony M M; Abdel Kader N M;\& Al-Batanony A.. Vaccination Coverage among health care workers in a tertiary care hospital - Saudi Arabia". Egyptian Journal of Occupational Medicine, 36, 1, 2012, 123-130. doi: 10.21608/ejom.2012.755.

25. Advisory Committee on Immunization Practices; Centers for Disease Control and Prevention (CDC). Immunization of healthcare personnel: recommendations of the Advisory Committee on Immunization Practices (ACIP). MMWR Recomm Rep 2011; 60 (RR-7):1-45; PMID:22108587.

26. Fortunato F, Tafuri S, Cozza V, Martinelli D \& Prato R. Low vaccination coverage among italian healthcare workers in 2013. Hum Vaccin Immunother.2015;11(1):133-9. doi: 10.4161/hv.34415. Epub 2014 Nov 1. PubMed PMID: 25483526; PubMed Central PMCID: PMC4514380.

27. Botelho-Nevers E, Cassir N, Minodier P, Laporte R, Gautret P, Badiaga S, Thiberville D, Ninove L, Charrel R \& Brouqui P. Measles among healthcare workers: a potential for nosocomial outbreaks. Euro Surveill. 2011;16(2):pii=19764. Available from: http://www.

eurosurveillance.org/ViewArticle.aspx?

ArticleId $=19764$. (Last accessed November ,2018).

28. Monsel G, Rapp C, Duong TA, Farhi D, Bouaziz JD, Meyssonnier V, Mirkamali A,
Jaureguiberry S \& Caumes E. [Measles in adults: an emerging disease not sparing medical staff]. Ann Dermatol Venereol 2011; 138:10710; PMID:21333820; http://dx.doi.org/10.1016/j.

annder.2010.12.015.

29.Talaat M, Kandeel A, El-Shoubary W, Bodenschatz C, Khairy I, Oun S, \& Mahoney FJ. Occupational exposure to needlestick injuries and hepatitis B vaccination coverage among health care workers in Egypt. Am J Infect Control. 2003 Dec;31(8):469-74. PubMed PMID: 14647109.

30. Zayet HH; Ezz El-Din AM; Ahmed SM \& El-Khayat MR. Hepatitis B and C virus infection among health care workers in general surgery department, Assiut University Hospitals. Egyptian Journal of Occupational Medicine, 39, 1, 2015, 85-104. doi: 10.21608/ejom.2015.813.

31. Mansour E, Abdul-Rahim S, Batouty G, Zaghloul I \& Abdel-Hadi S. Integration of hepatitis B immunization in the Expanded Program on Immunization of the Child Survival Project. J Egypt Public Health Assoc. 1993;68(5-6):487-94. PubMed PMID: 7775876.

32. Tuckerman JL, Collins JE \& Marshall HS. Factors affecting uptake of recommended immunizations among health care workers in South Australia. Hum Vaccin Immunother. 2015;11(3):704-12. doi: 10.1080/21645515.2015.1008886. PubMed PMID:25715003; PubMed Central PMCID: PMC4514246.

33. Taddei, C., Ceccherini, V., Niccolai, G., Porchia, B. R., Boccalini, S., Levi, M., Tiscione, E., Santini, M. G., Baretti, S., Bonanni, P \& Bechini, A. (2014). Attitude toward immunization and risk perception of measles, rubella, mumps, varicella, and pertussis in health care workers working in 6 hospitals of Florence, Italy 2011. Human vaccines \& immunotherapeutics, 10(9), 2612-22. 